Published in final edited form as:

Cancer Epidemiol Biomarkers Prev. 2016 April ; 25(4): 634-639. doi:10.1158/1055-9965.EPI-15-0924.

\title{
Coffee Consumption and the Risk of Colorectal Cancer
}

\author{
Stephanie L. Schmit ${ }^{1,2}$, Hedy S. Rennert ${ }^{3}$, Gad Rennert ${ }^{3,4,5}$, and Stephen B. Gruber ${ }^{1,2}$ \\ ${ }^{1}$ USC Norris Comprehensive Cancer Center, University of Southern California, Los Angeles, \\ California \\ ${ }^{2}$ Department of Preventive Medicine, Keck School of Medicine, University of Southern California, \\ Los Angeles, California \\ ${ }^{3}$ Department of Community Medicine and Epidemiology, Carmel Medical Center, Haifa, Israel \\ ${ }^{4}$ Clalit Health Services National Cancer Control Center, Haifa, Israel \\ ${ }^{5}$ Bruce Rappaport Faculty of Medicine, Technion-Israel Institute of Technology, Haifa, Israel
}

\section{Abstract}

Background-Coffee contains several bioactive compounds relevant to colon physiology. Although coffee intake is a proposed protective factor for colorectal cancer (CRC), current evidence remains inconclusive.

\begin{abstract}
Methods-We investigated the association between coffee consumption and risk of CRC in 5,145 cases and 4,097 controls from the Molecular Epidemiology of Colorectal Cancer (MECC) study, a population-based case-control study in northern Israel. We also examined this association by type of coffee, by cancer site (colon and rectum), and by ethnic subgroup (Ashkenazi Jews, Sephardi Jews, and Arabs). Coffee data were collected by interview using a validated, semiquantitative food frequency questionnaire.
\end{abstract}

Results-Coffee consumption was associated with $26 \%$ lower odds of developing CRC [Odds Ratio (drinkers versus non-drinkers) $=0.74 ; 95 \%$ CI: $0.64-0.86 ; P<0.001]$. The inverse association was also observed for decaffeinated coffee consumption alone (OR=0.82; 95\% CI: 0.68-0.99; $P=0.04)$ and for boiled coffee (OR=0.82; 95\% CI: $0.71-0.94 ; P=0.004)$. Increasing consumption of coffee was associated with lower odds of developing CRC. Compared to $<1$ serving/day, intake of 1 to $<2$ servings/day ( $\mathrm{OR}=0.78 ; 95 \% \mathrm{CI}$ : $0.68-0.90 ; P<0.001)$, 2 to 2.5 servings/day ( $\mathrm{OR}=0.59$; 95\% CI: $0.51-0.68 ; P<0.001$ ), and $>2.5$ servings/day ( $\mathrm{OR}=0.46 ; 95 \%$ CI: $0.39-0.54 ; P<0.001)$ were associated with significantly lower odds of $\mathrm{CRC}\left(P_{\text {trend }}<0.001\right)$, and the dose-response trend was statistically significant for both colon and rectal cancers.

Conclusions-Coffee consumption may be inversely associated with risk of CRC in a doseresponse manner.

Impact-Global coffee consumption patterns suggest potential health benefits of the beverage for reducing the risk of CRC.

Corresponding Author: Stephen B. Gruber, MD, PhD, USC Norris Comprehensive Cancer Center, 8302L Ezralow Tower, University of Southern California, Los Angeles, CA 90089, Phone: (323) 865-0816, ; Email: sgruber@usc.edu, Fax: (323) 865-0102.

Conflicts of Interest: The authors have no conflicts of interest to disclose. 


\section{Keywords}

Coffee; colorectal cancer; protective factor; nutraceutical; diet

\section{INTRODUCTION}

Coffee is one of the most widely-consumed beverages in the world $(1,2)$. It contains many potentially bioactive components that are relevant to colon physiology including polyphenols (mainly chlorogenic acids), melanoidins, diterpenes, and caffeine, among others $(3,4)$. Although the levels of these compounds vary by species of coffee bean, degree of roasting, brewing technique, and serving size, exposure to one or more of them may promote colon health via anti-mutagenic or antioxidant properties, reduction of bile acid secretion, modification of microbiome composition, and/or enhancement of critical bowel functions (e.g. motility, stool output) (3). Based on the potential benefits of coffee's biochemical components, the beverage has been proposed as a protective agent for colorectal cancer (CRC), the third most common cancer in males and in females in the United States (5) and the fourth most common cause of cancer death worldwide (6).

Despite the biological plausibility of coffee's chemopreventive properties, epidemiologic evidence of an association between coffee intake and the risk of CRC remains inconclusive. Existing evidence generally supports an inverse association, but results reported in the literature vary by study design (case-control versus cohort), cancer site (colon versus rectum), sex, and ethnicity (3, 7-18). The most recent meta-analysis considered 25 casecontrol studies and 16 cohort studies with over 25,000 cases (14). This meta-analysis observed suggestive evidence of an inverse association in cohort studies, whereas casecontrol studies showed that the highest category of coffee consumption was associated with a statistically significant $15-21 \%$ lower risk of CRC or colon cancer (not rectal cancer) as compared to the lowest category of consumption. Further, a growing body of evidence suggests coffee consumption as a protective factor for other gastrointestinal cancers (19-21). The goal of the current investigation was to examine the association between coffee intake and risk of CRC in a well-powered study with comprehensive data on clinical characteristics including anatomic site, coffee preparation, and potential confounders.

\section{MATERIALS AND METHODS}

\section{Study Description}

The Molecular Epidemiology of Colorectal Cancer Study (MECC) is a population-based, incidence-density case-control study of pathologically-confirmed incident CRC cases and their matched controls from a geographically-defined area of northern Israel (22). Subject recruitment began in 1998 and remains on-going. Individually-matched controls with no personal history of CRC are selected from the Clalit Health Services database to ensure representation of the same source population that gives rise to cases. Clalit Health Services is the largest health care provider in Israel, covering more than $70 \%$ of the study cases and providing a nationally-standardized health services basket. Matching factors include year of birth, sex, primary clinic location, and ethnicity (Jewish vs. non-Jewish). Subjects are 
interviewed within 6 months of diagnosis to obtain demographic data, clinical information, family history, and dietary habits. The present analysis included 5,145 cases and 4,097 controls with high-quality food frequency questionnaire data, for a total of 9,242 MECC study participants (Table 1). Written informed consent was obtained at the time of enrollment according to Institutional Review Board-approved protocols at Carmel Medical Center (Haifa) and the University of Southern California.

\section{Assessment of Coffee Consumption}

Coffee intake data were collected by in-person interview using a validated, semi-quantitative food frequency questionnaire adapted to the Israeli population. The questionnaire assessed the frequency of consumption of decaffeinated coffee, boiled black coffee, black coffee (espresso), instant coffee, and filter coffee one year prior to diagnosis for cases or interview for controls. The questionnaire also assessed intake of tea and other beverages, allowing for the calculation of total liquid consumption. To assure high quality data for analysis, 200 individuals with missing or extreme values for energy consumption (total caloric intake $<600$ or $>4000$ ) were excluded. Intake of each coffee type was calculated by converting a semiquantitative scale into servings per day, and total daily consumption was calculated by summing servings per day of decaffeinated, boiled, espresso, instant, and filter coffees. Further, 130 participants without complete data for all five coffee types and 24 outliers with total coffee consumption greater than four standard deviations from the mean were excluded. Finally, total coffee intake was converted into two derived variables: 1$)$ drinkers ( $>0$ servings/day) and non-drinkers (0 servings/day); and 2) ordered categories of coffee drinking informed by quartiles of consumption in controls. These four categories consisted of $<1$ serving/day (reference category), $\geq 1$ and $<2$ servings/day, $\geq 2$ and $\leq 2.5$ servings/day, and $>2.5$ servings/day.

\section{Statistical Analysis}

The associations between total coffee consumption and established CRC-associated risk and protective factors were examined using chi-squared tests of independence and analysis of variance. The association between coffee and CRC was assessed using unconditional and conditional logistic regression, with adjustment for known CRC risk factors. The inclusion criteria for covariates were study matching factors (for unconditional analyses) and those with a statistically significant association with CRC identified in prior published analyses of the MECC data. The covariates included were age, sex, ethnicity (Jewish vs. non-Jewish), family history of CRC in a first degree relative, vegetable consumption ( $\geq 5$ servings/day vs. $<5$ servings/day), sports participation (yes vs. no), statin use (duration $\geq 5$ years vs. $<5$ years), daily low-dose aspirin use (duration $\geq 2$ years vs. $<2$ years), and smoking status (current/former/never). We conducted a test for trend based on an ordinal score corresponding to the four categories of daily coffee consumption described above. The associations were further explored with stratification by ethnic subgroup (Ashkenazi Jews, Sephardi Jews, and Arabs), cancer site (colon and rectum), and type of coffee (decaffeinated, boiled, espresso, instant, and filtered). 


\section{RESULTS}

The demographic and clinical characteristics of the study participants for analysis are summarized in Table 1. Findings reported here are based on analyses of 5,145 cases and 4,097 controls (with 3,574 matched pairs for conditional logistic regression). The majority of participants were of Ashkenazi Jewish descent (61.3\%), with individuals of Sephardi Jewish (21.4\%) and Arab (13.5\%) descent comprising the other major ethnic subgroups. As compared to controls, on average, cases were slightly younger (matched for age within 1 year), were less likely to take statins or low dose aspirin, were less likely to be physically active, were less likely to consume 5 or more servings of vegetables per day, were less likely to smoke, and had a stronger family history of CRC. Overall, $74 \%$ of all incident cases in the source population were identified and approached, and $84 \%$ of these agreed to participate (case participation rate $=62 \%$ ). Among population-based controls, the participation rate was $52 \%$.

The mean total coffee intake among controls was 2.0 servings per day. Arabs had the highest total consumption with an average of 3.3 servings per day, followed by Sephardi Jews with a mean of 2.1 servings per day, and finally by Ashkenazi Jews with an average of 1.8 servings per day. Total coffee consumption in the complete sample, stratified by major ethnic group, can be visualized in Figure 1. Mean coffee consumption was statistically significantly different across these 3 groups $(P<0.001)$. Instant coffee was the most common type consumed by Ashkenazi and Sephardi Jews, whereas boiled coffee was the most popular among Arabs (Supplementary Figure 1). Total coffee consumption was associated with established CRC-associated factors: vegetable consumption $(P<0.001)$, daily low-dose aspirin use $(P=0.03)$, sports participation (; $P<0.001)$, smoking status $(P<0.001)$, and sex $(P<0.001)$.

Table 2 summarizes the unconditional logistic regression results for coffee consumption and risk of cancer, comparing coffee drinkers to non-drinkers. The results from matched analyses of 3,574 pairs were not qualitatively different from those conducted using an unconditional approach, so we present unmatched analyses due to power considerations. Coffee consumption was associated with a $26 \%$ reduction in the odds of developing CRC after adjusting for study matching factors and other known risk-associated factors [OR (drinkers of any amount versus non-drinkers): $0.74 ; 95 \%$ confidence interval (CI): $0.64-0.86$; $P<0.001]$. Additional adjustment for total daily liquid consumption yielded a comparable overall CRC adjusted OR [0.80; 95\% CI: $0.68-0.93 ; P=0.005]$, indicating that liquid intake did not account for the observed association. Adjustment for total calorie consumption in addition to matching factors and known risk factors also yielded a comparable OR [0.74; 95\% CI: $0.63-0.86 ; P<0.001]$. Upon stratification by coffee type, an inverse association was maintained for those consuming decaffeinated coffee [overall $\mathrm{CRC}$ adjusted $\mathrm{OR}=0.82 ; 95 \%$ CI: $0.68-0.99 ; P=0.04]$ as well as boiled coffee (overall $\mathrm{CRC}$ adjusted $\mathrm{OR}=0.82 ; 95 \% \mathrm{CI}$ : $0.71-0.94 ; P=0.004$; Table 3 ).

Upon stratification by ethnic subgroup, the OR estimates for Ashkenazi Jews, Sephardi Jews, and Arabs were consistent with the total sample. Results were statistically significant for only Ashkenazi Jews and Sephardi Jews, the two largest ethnic subgroups represented in 
the MECC study (Table 2). When considering colon and rectal cancers separately, the OR estimates show an inverse association between coffee consumption and risk of cancer in either tumor location. These estimates were highly statistically significant in the total sample and in Sephardi Jews. In the total MECC sample, the association for rectal cancer was attenuated as compared to that for colon cancer but approached statistical significance at the $P<0.05$ level [OR $=0.80 ; 95 \%$ CI: $0.62-1.01 ; P=0.06$ ]. In addition, we did not observe evidence of meaningful effect modification of the association of coffee consumption and risk of CRC by other covariates, including sex, vegetable consumption, physical activity, statins, aspirin, smoking, or family history, with the exception of age $\left[\mathrm{OR}_{\text {interaction }}=1.01 ; 95 \% \mathrm{CI}\right.$ : $1.00-1.03 ; P=0.04]$.

Table 4 summarizes logistic regression results when considering daily total coffee intake in four categories. Compared with drinkers of $<1$ serving/day, drinkers of 1 to $<2$ servings/day (OR: 0.78 ; $95 \%$ CI: $0.68-0.90 ; P<0.001$ ), 2 to 2.5 servings/day (OR: 0.59 ; $95 \%$ CI: $0.51-$ $0.68 ; P<0.001$ ), and $>2.5$ servings/day (OR: $0.46 ; 95 \%$ CI: $0.39-0.54 ; P<0.001)$ had statistically significant lower odds of developing CRC in the total MECC sample. Notably, we observed an inverse dose-response relation between coffee intake and odds of developing CRC $\left(P_{\text {trend }}<0.001\right)$. When colon and rectal cancers were examined individually, the direction and magnitude of ORs for all non-reference categories remained essentially unchanged from CRC estimates and were highly statistically significant. Table 4 also details the same set of analyses stratified by ethnic subgroup. The statistically-significant inverse dose-response relation between coffee and risk of CRC, colon, or rectal cancers held in the two largest ethnic subgroups (Ashkenazi and Sephardi Jews). Although power was limited for the analysis of Arab participants, consistent directions of OR point estimates were observed.

\section{DISCUSSION}

Here, we demonstrate that modest coffee consumption ( $>=1$ and $<2$ servings/day) is associated with a meaningful reduction in the odds of developing CRC in a large, population-based case-control study, and that the highest category of consumption ( $>2.5$ servings/day) is associated with a 54\% reduction in odds of developing disease. The inverse association was consistent for decaffeinated and boiled coffees, colon and rectal cancers, and observed among all ethnic subgroups in our study. Evidence of a dose response relation with greater risk reduction associated with increasing consumption supports the biological plausibility of these findings.

The results from this study support the growing body of evidence suggesting coffee consumption as a protective factor for CRC $(11,15,23)$ and as a predictor of reduced CRC recurrence and death (24). However, there are differences in results and interpretations of case-control and cohort studies $(14,18)$, possibly due to the different time period of exposure considered relative to cancer diagnosis. A subgroup analysis of cohort studies showed that studies with less than 10 years of follow-up were more likely to report an inverse association between coffee consumption and risk of CRC than those with follow-up longer than 10 years (15). With respect to dose, our finding of a statistically significant inverse association was observed at lower levels of coffee intake than some previous 
publications. For example, a recent dose-response analysis observed a statistically significant inverse relation associated with $\geq 4$ cups/day (12), and another study in a Japanese population showed a $\mathrm{U}$-shaped relation between coffee and CRC with decreased risk for up to 3 cups/day (25). In contrast to several earlier reports observing no statistically significant association for rectal cancer, our study demonstrated an inverse trend for both colon and rectal cancers $(11,12,14)$. This difference is possibly due in part to a lack of power in prior studies.

A variety of potentially bioactive compounds in coffee could independently or in combination exert chemopreventive properties, and thus, several mechanisms of action have been proposed. Coffee constituents could influence colon health via roles in motility and fecal output, microbiome composition, inflammation, secretion of bile acids, insulin sensitivity, and the oxidative environment of the colon (26) With respect to specific components, chlorogenic acids are powerful antioxidants in vitro and are believed to modify expression of genes encoding phase II metabolism enzymes as well as to inhibit DNA methyltransferase (27). Polyphenols are hypothesized to exert antioxidant and antiproliferative effects as well as to induce cell cycle arrest based on experimental evidence in CRC cell lines (28). The roasting products, melanoidins, may act in vivo as dietary fiber and could increase colon motility (27). The diterpenes cafestol and kahweol are plentiful in boiled and unfiltered coffees and may exert anticarcinogenic activity by enhancing defense systems against oxidative damage $(7,27,29)$. Our finding of an inverse association for boiled coffee provides epidemiologic evidence in support of the protective role of these biochemical components. Caffeine may have antioxidant capacity (27), and it may limit the growth potential of human colon cancer cells (30). Our observation that an inverse association was present for decaffeinated coffee alone indicates that caffeine is unlikely to be the sole compound underlying coffee's protective properties.

Levels of exposure to these different compounds vary based on the type of coffee bean, roasting degree, brewing technique, and serving size. For example, cafestol and kahweol are removed by filtration, and thus, filter and instant coffee contain very little $(4,31)$. Further, more melanoidins are present in darker roasted coffees and those with higher powder/water ratio during the brewing process (26). Serving size has been shown to be the most important factor for intake of chlorogenic acids and melanoidins $(3,32)$. The lack of detailed information collected by most food frequency questionnaires makes it difficult to discern in an observational setting which coffee component(s) are important. Few population-scale studies have focused on dietary intake of specific potentially bioactive components. However, one recent Japanese study demonstrated a decreased risk of CRC associated with coffee polyphenol intake (25). Relevant to our study, it is possible that differences in the strength of association between coffee consumption and CRC across ethnic subgroups could be driven in part by the different distribution of coffee types and serving sizes consumed.

Our study has several strengths as compared to prior investigations of the role of coffeedrinking and risk of developing CRC. Two major benefits include exceptional power to allow for stratified analyses and detailed questionnaire data to enable the analysis of different coffee types. We also evaluated caffeine status and indirectly investigated brewing methods of decoction (for boiled coffee) and gravitation (for filter coffee), which most prior 
studies have not been able to accomplish. Despite these strengths, our study was limited by a number of factors. Unlike prospective cohort study designs, data were collected for our casecontrol study at one point in time regarding usual coffee consumption one year prior to diagnosis, and thus, we could not assess duration of exposure. Further, no standardized measurements for serving size were available. Limitations of the observational nature of case-control designs, including the use of food frequency recall, also need to be considered in the interpretation of these results. Notably, we observed consistent results upon stratification by stage at diagnosis, alleviating concerns that recall bias may be more severe for patients with more advanced disease. Alternative explanations for an inverse association between coffee consumption and CRC include reverse causation, with digestive tract disease and bowel symptoms leading cases to avoid drinking coffee (14), and the possibility that total fluid consumption or hot beverage drinking may reduce risk of CRC through a mechanism of increased colon motility. However, we observed that controlling for total beverage consumption did not attenuate the inverse relation between coffee and CRC. All case-control studies are potentially vulnerable to residual confounding, including ours, and it is possible that measured or unmeasured risk factors might lead to biased estimates of the association between coffee consumption and risk of colorectal cancer.

In conclusion, this large case-control study provides evidence of an inverse, dose-response association between coffee drinking and the odds of CRC, colon, and rectal cancer incidence. It also suggests that caffeine is not the critical component responsible for this inverse association and that the protective association was not observed for filtered or instant coffees. The health risks of coffee consumption are low, but additional evidence is warranted before advocating for coffee consumption as a nutraceutical approach to reduce the risk of CRC.

\section{Supplementary Material}

Refer to Web version on PubMed Central for supplementary material.

\section{Acknowledgments}

Financial Support: This work was supported by the National Cancer Institute at the National Institutes of Health [R01 CA81488, U19 CA148107, and P30 CA014089 to S.B. Gruber] and the National Institute of Environmental Health Sciences at the National Institutes of Health [T32 ES013678 to S.L. Schmit].

\section{References}

1. Food and Agriculture Organization of the United Nations Statistics Division. Food Balance Sheets: World. FAOSTAT; 2011.

2. Butt MS, Sultan MT. Coffee and its consumption: benefits and risks. Crit Rev Food Sci Nutr. 2011; 51:363-73. [PubMed: 21432699]

3. Vitaglione P, Fogliano V, Pellegrini N. Coffee, colon function and colorectal cancer. Food Funct. 2012; 3:916-22. [PubMed: 22627289]

4. Ludwig IA, Clifford MN, Lean ME, Ashihara H, Crozier A. Coffee: biochemistry and potential impact on health. Food Funct. 2014; 5:1695-717. [PubMed: 24671262]

5. Howlader, N.; Krapcho, M.; Neyman, N.; Aminou, R.; Altekruse, SF.; Kosary, CL., et al., editors. SEER Cancer Statistics Review, 1975-2009 (Vintage 2009 Populations), based on November 2011 SEER data submission. 2012. http://seer.cancer.gov/csr/1975_2009_pops09/ 
6. J SH, Ferlay; Bray, F.; Forman, D.; Mathers, C.; Parkin, DM. GLOBOCAN 2008 v1.2, Cancer Incidence and Mortality Worldwide: IARC CancerBase No. 10 [Internet]. 2010. http:// globocan.iarc.fr

7. Nkondjock A. Coffee consumption and the risk of cancer: an overview. Cancer Lett. 2009; 277:1215. [PubMed: 18834663]

8. Arab L. Epidemiologic evidence on coffee and cancer. Nutr Cancer. 2010; 62:271-83. [PubMed: 20358464]

9. Yamada H, Kawado M, Aoyama N, Hashimoto S, Suzuki K, Wakai K, et al. Coffee Consumption and Risk of Colorectal Cancer: The Japan Collaborative Cohort Study. J Epidemiol. 2014; 24:3708. [PubMed: 24857957]

10. Giovannucci E. Meta-analysis of coffee consumption and risk of colorectal cancer. Am J Epidemiol. 1998; 147:1043-52. [PubMed: 9620048]

11. Galeone C, Turati F, La Vecchia C, Tavani A. Coffee consumption and risk of colorectal cancer: a meta-analysis of case-control studies. Cancer Causes Control. 2010; 21:1949-59. [PubMed: 20680435]

12. Tian C, Wang W, Hong Z, Zhang X. Coffee consumption and risk of colorectal cancer: a doseresponse analysis of observational studies. Cancer Causes Control. 2013; 24:1265-8. [PubMed: 23546611]

13. Yu X, Bao Z, Zou J, Dong J. Coffee consumption and risk of cancers: a meta-analysis of cohort studies. BMC Cancer. 2011; 11:96. [PubMed: 21406107]

14. Li G, Ma D, Zhang Y, Zheng W, Wang P. Coffee consumption and risk of colorectal cancer: a meta-analysis of observational studies. Public Health Nutr. 2013; 16(2):346-57. [PubMed: 22694939]

15. Je Y, Liu W, Giovannucci E. Coffee consumption and risk of colorectal cancer: a systematic review and meta-analysis of prospective cohort studies. Int J Cancer. 2009; 124:1662-8. [PubMed: 19115212]

16. Tavani A, La Vecchia C. Coffee, decaffeinated coffee, tea and cancer of the colon and rectum: a review of epidemiological studies, 1990-2003. Cancer Causes Control. 2004; 15:743-57. [PubMed: 15456988]

17. Ekbom A. Review: substantial coffee consumption was associated with a lower risk of colorectal cancer in the general population. Gut. 1999; 44:597. [PubMed: 10205191]

18. Zhang X, Albanes D, Beeson WL, van den Brandt PA, Buring JE, Flood A, et al. Risk of colon cancer and coffee, tea, and sugar-sweetened soft drink intake: pooled analysis of prospective cohort studies. J Natl Cancer Inst. 2010; 102:771-83. [PubMed: 20453203]

19. Setiawan VW, Wilkens LR, Lu SC, Hernandez BY, Le Marchand L, Henderson BE. Association of coffee intake with reduced incidence of liver cancer and death from chronic liver disease in the US multiethnic cohort. Gastroenterology. 2015; 148:118-25. [PubMed: 25305507]

20. Bravi F, Bosetti C, Tavani A, Gallus S, La Vecchia C. Coffee reduces risk for hepatocellular carcinoma: an updated meta-analysis. Clin Gastroenterol Hepatol. 2013; 11:1413-1421. [PubMed: 23660416]

21. Sang LX, Chang B, Li XH, Jiang M. Consumption of coffee associated with reduced risk of liver cancer: a meta-analysis. BMC Gastroenterol. 2013; 13:34. [PubMed: 23433483]

22. Poynter JN, Gruber SB, Higgins PD, Almog R, Bonner JD, Rennert HS, et al. Statins and the risk of colorectal cancer. N Engl J Med. 2005; 352:2184-92. [PubMed: 15917383]

23. Ainslie-Waldman CE, Koh WP, Jin A, Yeoh KG, Zhu F, Wang R, et al. Coffee intake and gastric cancer risk: the Singapore Chinese health study. Cancer Epidemiol Biomarkers Prev. 2014; 23:638-47. [PubMed: 24608187]

24. Guercio BJ, Sato K, Niedzwiecki D, Ye X, Saltz LB, Mayer RJ, et al. Coffee Intake, Recurrence, and Mortality in Stage III Colon Cancer: Results From CALGB 89803 (Alliance). Journal of Clinical Oncology. 2015 Epub 10.1200/JCO.2015.61.5062.

25. Wang ZJ, Ohnaka K, Morita M, Toyomura K, Kono S, Ueki T, et al. Dietary polyphenols and colorectal cancer risk: the Fukuoka colorectal cancer study. World J Gastroenterol. 2013; 19:268390. [PubMed: 23674876] 
26. Bai Y, Yuan H, Li J, Tang Y, Pu C, Han P. Relationship between bladder cancer and total fluid intake: a meta-analysis of epidemiological evidence. World J Surg Oncol. 2014; 12:223. [PubMed: 25033957]

27. Cao S, Liu L, Yin X, Wang Y, Liu J, Lu Z. Coffee consumption and risk of prostate cancer: a metaanalysis of prospective cohort studies. Carcinogenesis. 2014; 35:256-61. [PubMed: 24343360]

28. Araujo JR, Goncalves P, Martel F. Chemopreventive effect of dietary polyphenols in colorectal cancer cell lines. Nutr Res. 2011; 31:77-87. [PubMed: 21419311]

29. Cavin C, Holzhaeuser D, Scharf G, Constable A, Huber WW, Schilter B. Cafestol and kahweol, two coffee specific diterpenes with anticarcinogenic activity. Food Chem Toxicol. 2002; 40:115563. [PubMed: 12067578]

30. Merighi S, Benini A, Mirandola P, Gessi S, Varani K, Simioni C, et al. Caffeine inhibits adenosineinduced accumulation of hypoxia-inducible factor-1alpha, vascular endothelial growth factor, and interleukin-8 expression in hypoxic human colon cancer cells. Mol Pharmacol. 2007; 72:395-406. [PubMed: 17488804]

31. George SE, Ramalakshmi K, Mohan Rao LJ. A perception on health benefits of coffee. Crit Rev Food Sci Nutr. 2008; 48:464-86. [PubMed: 18464035]

32. Fogliano V, Morales FJ. Estimation of dietary intake of melanoidins from coffee and bread. Food Funct. 2011; 2:117-23. [PubMed: 21779556] 


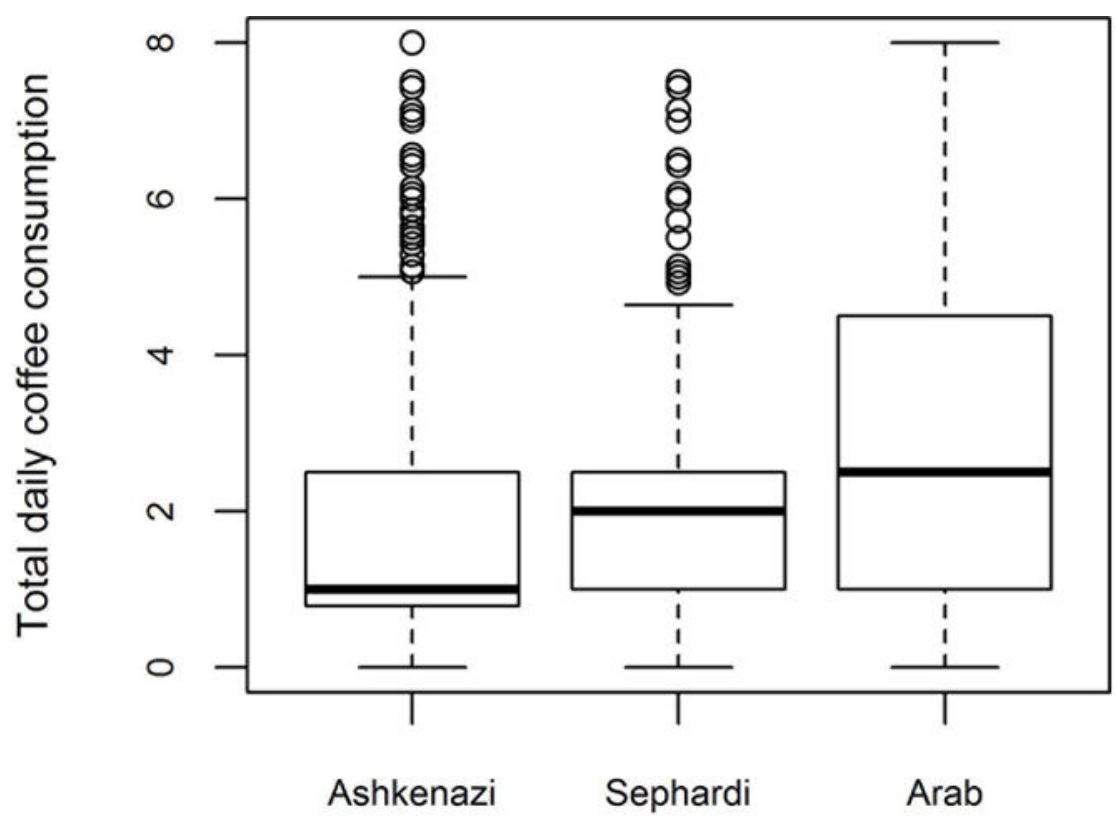

Figure 1.

Total daily coffee consumptions (servings/day) by major ethnic subgroup in the Molecular Epidemiology of Colorectal Cancer (MECC) Study. 
Table 1

Demographic and clinical characteristics of Molecular Epidemiology of Colorectal Cancer (MECC) study participants $(n=9,242)$.

\begin{tabular}{|c|c|c|c|c|}
\hline & \multicolumn{2}{|c|}{ Cases $(n=5,145)$} & \multicolumn{2}{|c|}{ Controls $(n=4,097)$} \\
\hline & $\mathbf{N}$ & $\%$ & $\mathbf{N}$ & $\%$ \\
\hline Age $[$ mean(sd)] & $68.7(12.2)$ & & $70.7(11.9)$ & \\
\hline \multicolumn{5}{|l|}{$\operatorname{Sex}(\%)$} \\
\hline Male & 2,689 & 52.3 & 2,121 & 51.8 \\
\hline Female & 2,456 & 47.7 & 1,976 & 48.2 \\
\hline \multicolumn{5}{|l|}{ Ethnicity (\%) } \\
\hline Ashkenazi & 3,248 & 63.1 & 2,416 & 59.0 \\
\hline Sephardi & 1,006 & 19.5 & 976 & 23.8 \\
\hline Arab & 764 & 14.8 & 487 & 11.9 \\
\hline Non-Jewish, Non-Arab & 126 & 2.4 & 59 & 1.4 \\
\hline Family history of CRC (first degree relative) & 447 & 8.7 & 242 & 5.9 \\
\hline Vegetable consumption (>=5/day) & 2,882 & 56.0 & 2,524 & 61.6 \\
\hline Sports activity & 1,454 & 28.3 & 1,680 & 41.0 \\
\hline Statins use, $5+$ years & 690 & 13.4 & 772 & 18.8 \\
\hline Daily aspirin use, $2+$ years & 1,009 & 19.6 & 1,188 & 29.0 \\
\hline \multicolumn{5}{|l|}{ Smoking Status } \\
\hline Current & 424 & 8.2 & 525 & 12.8 \\
\hline Former & 1,487 & 28.9 & 1,173 & 28.6 \\
\hline Never & 2,826 & 54.9 & 2,020 & 49.3 \\
\hline \multicolumn{5}{|l|}{ Site } \\
\hline Colon & 3,788 & 73.6 & - & - \\
\hline Rectum & 1,160 & 22.5 & - & - \\
\hline Other or Missing & 197 & 3.8 & - & - \\
\hline \multicolumn{5}{|l|}{ Stage } \\
\hline 1 & 385 & 7.5 & - & - \\
\hline 2 & 825 & 16.0 & - & - \\
\hline 3 & 586 & 11.4 & - & - \\
\hline 4 & 471 & 9.2 & - & - \\
\hline Missing ${ }^{*}$ & 2862 & 55.6 & - & - \\
\hline
\end{tabular}

* Although T and N staging was available for all cases, metastasis staging requires individual medical record review which is complete for only 2,267 cases. Medical record review continues.

$\mathrm{SD}=$ standard deviation $; \mathrm{CRC}=$ colorectal cancer . 


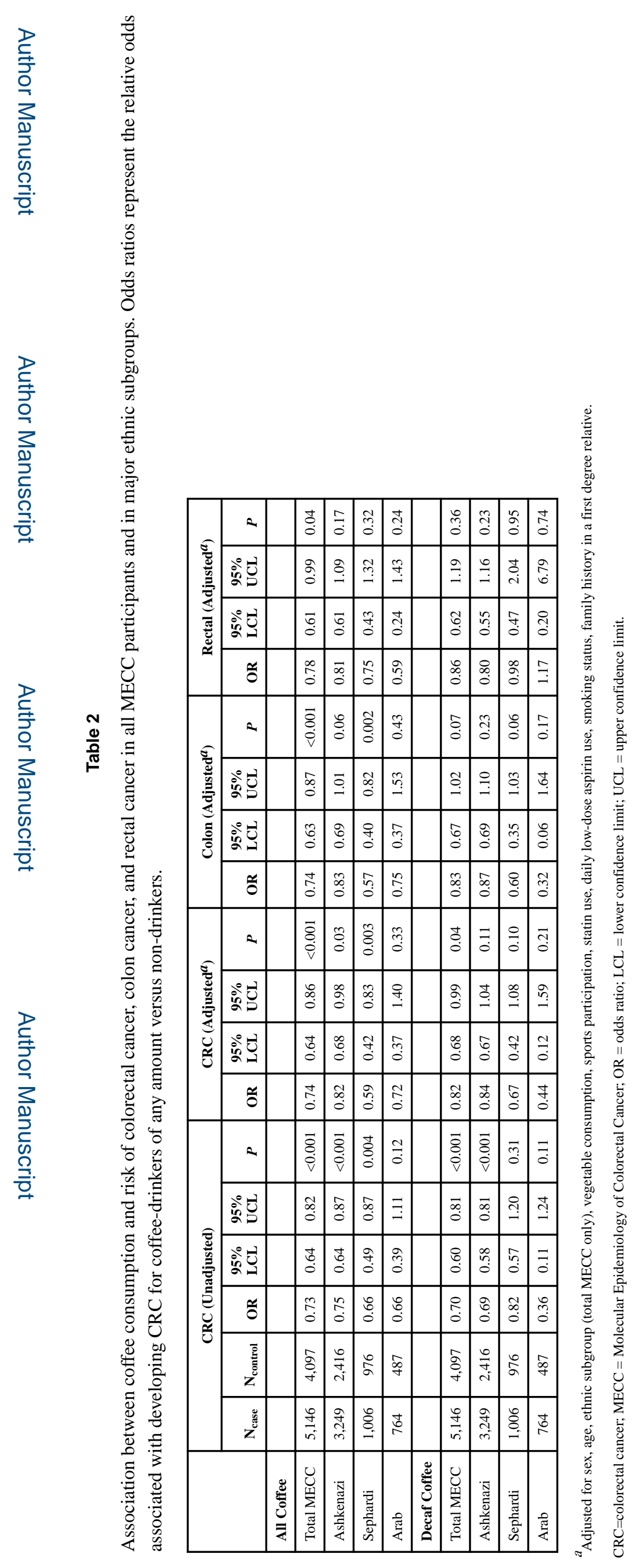




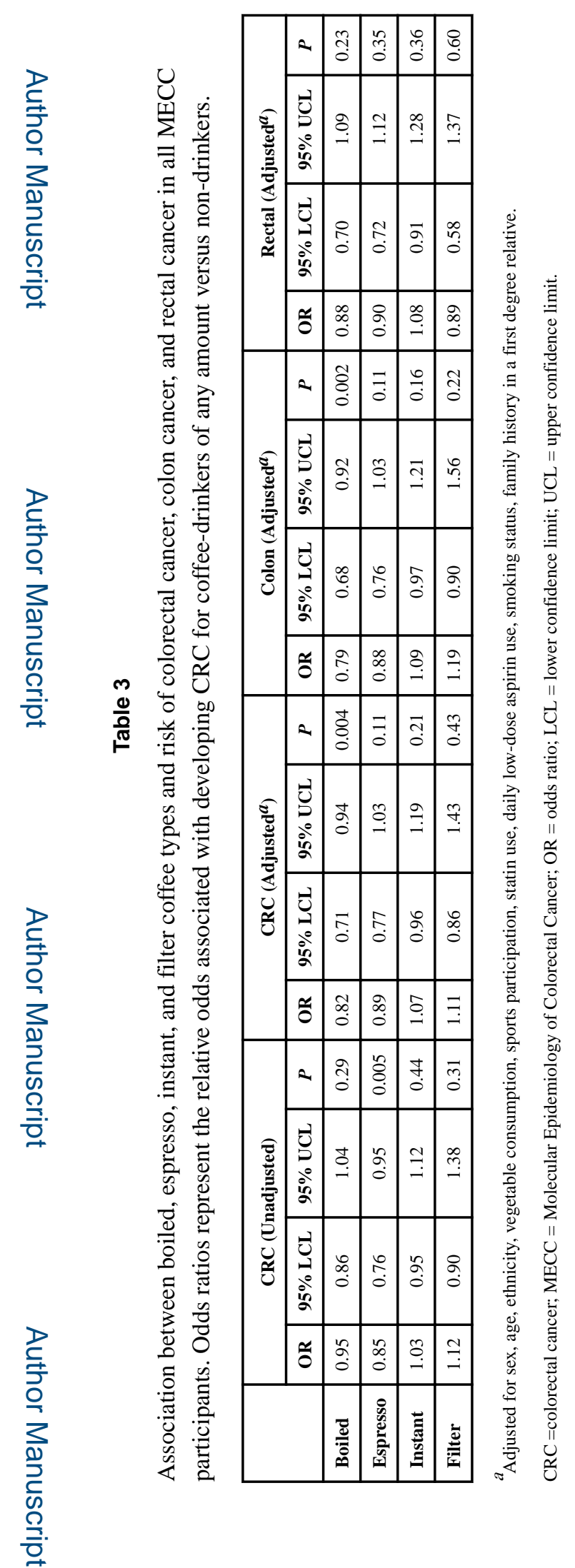

Cancer Epidemiol Biomarkers Prev. Author manuscript; available in PMC 2017 April 01. 


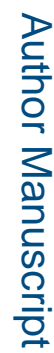

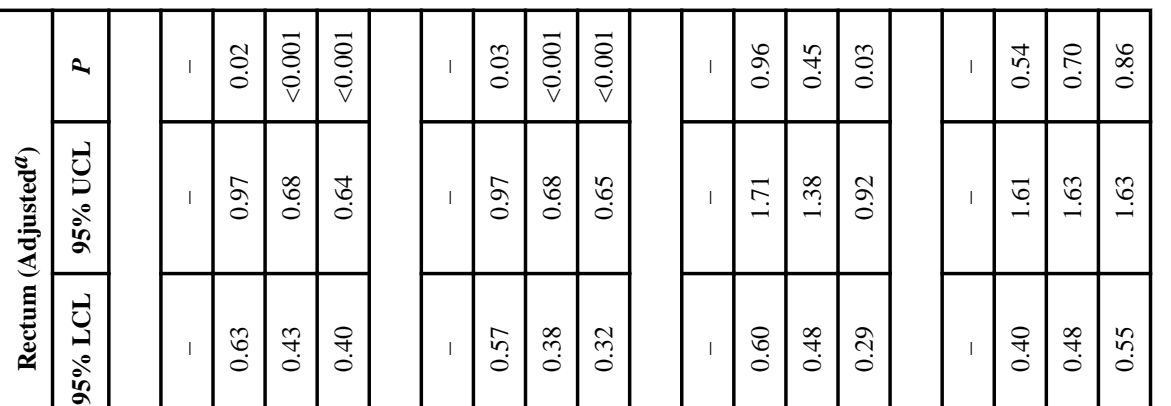

힘

已

ํㅡㅁ

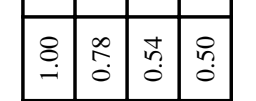

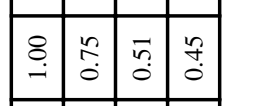

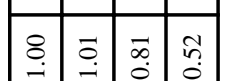

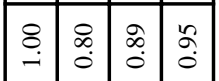

로을

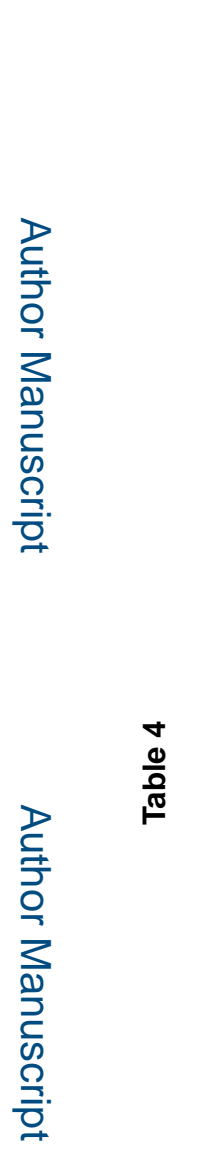

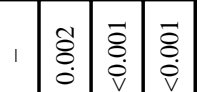

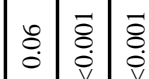

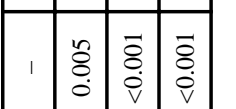

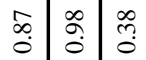

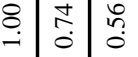

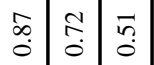

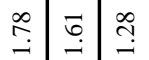

.

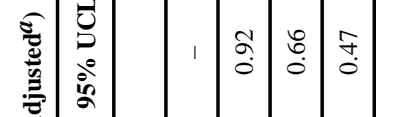

我

일

亦

\begin{tabular}{lll}
\hline & $\overrightarrow{0}$ & $\tilde{0}$ \\
\hdashline & 0 & 0 \\
0
\end{tabular}

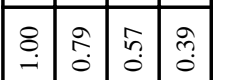

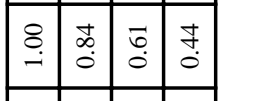

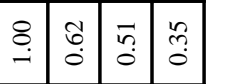

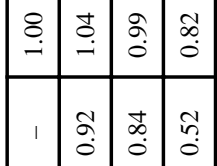

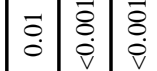

ลิ 충

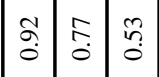

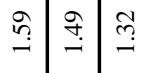

aे

守

$\begin{array}{lll}0 & \overline{0} & 0 \\ 0 & \stackrel{\infty}{0} & 0 \\ 0 & 0\end{array}$

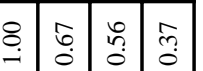

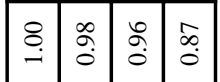

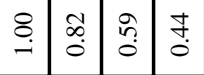

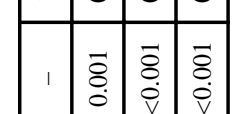

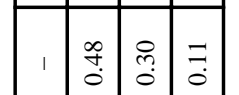

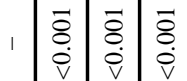

莺

紋.

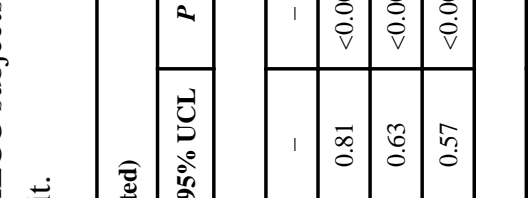

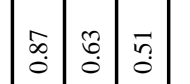

$\begin{array}{lll}0 & & \\ 0 & 0 & 0 \\ 0 & 0 & 0 \\ 0 & 0 & 0 \\ 0\end{array}$

ल․

离

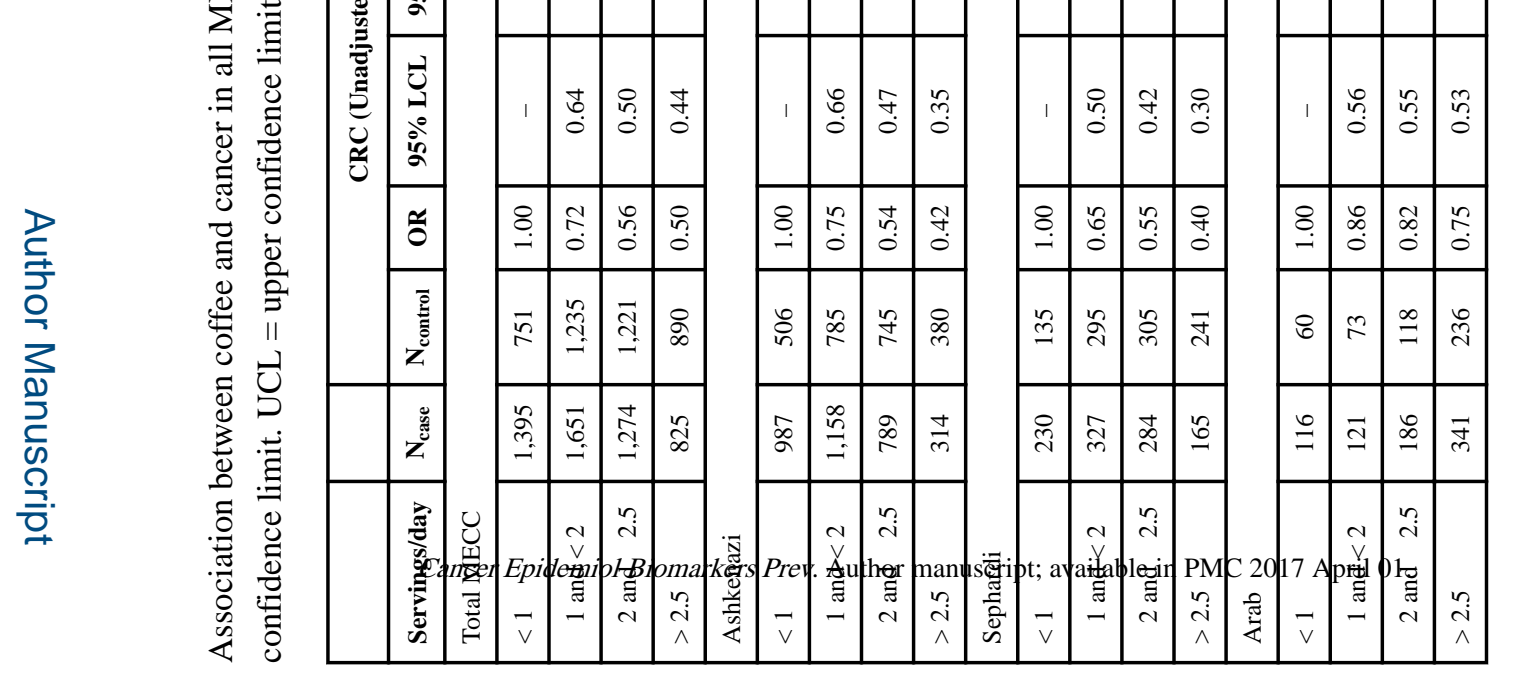

